\title{
MARTIN HEIDEGGER Y EL PARTICIPIO DE TODOS LOS PARTICIPIOS
}

\author{
Prof. Luis Ángel Lome Hurtado ${ }^{1}$ \\ Universidad Autónoma de México, UNAM, México
}

\begin{abstract}
Resumen: El artículo investiga la relevancia de la antigua palabra \&́óv dentro de la interpretación de Martin Heidegger a la filosofía griega. El çóv es la palabra más fundamental de la tradición occidental, pero fue olvidada desde el surgimiento de los conceptos fundamentales de la metafísica de Platón y Aristóteles. Desde la exégesis gramatical a la prehistoria de la metafísica (Homero, Anaximandro, Parménides, Heráclito), Heidegger recupera la significación de la antigua palabra ćóv y su resultado es que ella se presenta como el hilo conductor del pensamiento del ser dentro de la historia del ser. La ontología fenomenológica de Heidegger ejecuta una hermenéutica de los textos fundamentales de la tradición metafísica para desvelar la intuición fenomenológica del ser desde la palabra ćóv, el cual pasa por ser el participio de todos los participios.
\end{abstract}

Descriptores: Participio $\cdot$ Ser $\cdot$ Ente $\cdot$ Intuición $\cdot$ Fenomenología

\begin{abstract}
This paper researches the relevance of the ancient word غ̇óv on Heidegger's interpretation of the Greek philosophy. The Éov is the more fundamental word of the Western tradition, but it was forgotten since the emergence of the basic concepts of PlatoAristotle's metaphysics. Since the grammatical exegesis to the prehistory of metaphysic (Homer, Anaximander, Parmenides, Heraclitus), Heidegger recovered the signification of the ancient word غ́óv and his result is that the word appears as the common thread of thought of being within the history of being. Heidegger's ontological phenomenology carries out a hermeneutic of the fundamental texts of metaphysical tradition to disclose the phenomenological intuition of being from the word \&́óv, which is the participle of the all participles.
\end{abstract}

Keywords: Participle $\cdot$ Being $\cdot$ Entity $\cdot$ Intuition $\cdot$ Phenomenology

Enviado: 26/11/2018. Aceptado:01/04/2019

Fue cierta la aseveración de que el futuro de la fenomenología sería ontología y de que ésta necesitaría pasar por la gramática para poder encontrar el hilo conductor

\footnotetext{
${ }^{1}$ Profesor en la Facultad de Estudios Superiores Acatlán, UNAM, México. Programa de doctorado Instituto de Investigaciones Filosóficas "Luis Villoro", Universidad Michoacana de San Nicolás de Hidalgo, UMSNH, México. E-mail: luislome@yahoo.com.mx
} 
hacia la "cosa misma", y con ello, hacer a un lado los meros cuentos. ${ }^{2}$ El sendero heideggeriano del pensar acerca del ser tomó como punto de partida diferentes palabras clave para la interpretación de las épocas de la tradición filosófica, tales como la relación de subjetividad-objetividad en la modernidad, las nociones de creaciónfundamento-infinitud de la teología medieval, la noción de sustancia de Aristóteles y la idea o forma de Platón (Gillespie, 1984, p. 136). Este carácter epocal de la manifestación del ser se presenta a través de diversas palabras conductoras y con ello, de acuerdo con una visión filosófica de la historia, ellas hablan de lo mismo. Eso llamado "lo mismo" fue un lema exegético heideggeriano, el cual decía que cada pensador piensa un único pensamiento a través de una palabra fundamental, la cual obedecía a una huella propia de la historia de la metafísica como constitución onto-teo-lógica. ${ }^{3}$ Esto que pasa a ser "lo mismo" se presenta como ese sello de la tradición moderna, al modo de una deuda que hace época y destino del pensar humano estructurada bajo diversos aspectos y directrices como la confusión del ser por el ente, la búsqueda del fundamento último, el principio de razón suficiente, la versión lógica de la metafísica, la exposición conceptual como unidad de lo real y lo ideal, y la voluntad como última configuración de la modernidad. Pero dicha configuración de la metafísica no sólo alcanza la época moderna, sino que proviene de la edad media y la antigüedad greco-romana; sin olvidar que la última configuración de dicho olvido se manifiesta como la autoexposición del nihilismo más puro transformado por la estructura de emplazamiento (Gestell) de la técnica moderna-contemporánea (Heidegger, 2000b, p. 386).

La superación de la metafísica como onto-teo-logía no sólo incluye esa característica central de la epoché fenomenológica al momento de volver hacia los fenómenos mismos, sino que se dirige primordialmente hacia la historicidad y la hermenéutica del pensamiento filosófico, cuyo regreso a los presocráticos representa para las vías del pensar de Heidegger una posibilidad, la cual es más alta que la realidad (Heidegger, 2006, p. 61/Volpi, 2011), y con ello, proporciona una interpretación del ser que se sustrae a la tradición metafísica, la cual es nihilismo y olvido del ser. Ese retorno a Parménides, Heráclito y Anaximandro posee una orientación crucial y, con ello, existe una forma de pensar originaria como salto y retorno hacia lo dicho en la

\footnotetext{
${ }^{2}$ En el “\$7. El método fenomenológico de la investigación” de Ser y tiempo se dice acerca de la tarea propia de la fenomenología heideggeriana: "una cosa es hablar en forma narrativa sobre el ente y otra, captar el ente en su ser. Para este último cometido, con frecuencia faltan no sólo las palabras, sino sobre todo la "gramática"” (p. 61).

${ }^{3}$ Cf. Las lecciones de 1936 que componen el Tratado de Schelling sobre la esencia de la libertad humana (2015a) y el escrito de 1956-1957 llamado "La constitución onto-teo-lógica de la metafísica" (2008c); en ellos, Heidegger se dirige hacia la consideración de que toda filosofía es metafísica y de que ésta está determinada por una constitución "onto-teo-lógica"; esto quiere decir que el objeto principal de la meditación metafísica toma al ser como un ente (ón), y éste se entiende desde la consideración del ente supremo (theós) y su lógos desde una exposición lógica o conceptual.
} 
prehistoria de la metafísica. La actitud ontológica de la fenomenología heideggeriana se dirige hacia el esclarecimiento de las antiguas intuiciones del ser dentro de las palabras fundamentales de aletheia, physis, lógos, las cuales aparecen veladas, ocultas, distorsionadas por la tradición y los primeros posicionamientos metafísicos llevados a cabo por las categorías platónico-aristotélicas. De esa serie de interpretaciones surgen los trabajos heideggerianos acerca del significado de la verdad en Platón, de la configuración del sentido pre-teorético del lógos apophantikós, de la emergencia y ocultamiento de los fenómenos mismos a partir de la dilucidación de la physis. ${ }^{4}$ Pero dentro de los análisis e interpretaciones de la filosofía griega antigua y más precisamente, del regreso a los presocráticos y los antiguos poetas se pueden hallar las elaboraciones hermenéuticas más radicales, enigmáticas y poéticas de la tragedia heideggeriana del ser, como ocurre con la palabra olvidada éóv, la cual es considerada como la clave o llave fenomenológica para la reactivación de las cosas mismas debido a su potencialidad de ser el participio de todos los participios y, con ello, contener la intuición más originaria del ser. ¿Qué revela la palabra દ̇óv dentro del pensamiento del ser? Esta dilucidación conduce hacia su esclarecimiento dentro de las diversas exégesis que Martin Heidegger realizó a lo largo de su camino del pensar acerca del ser dentro de la historia del ser.

El tratado fundamental Ser y tiempo de 1927 desplegó la recuperación del significado del ser como el asunto principal no sólo de la investigación fenomenológica del siglo XX, sino de toda la tradición filosófica, la cual, al modo de un destino (Moira) olvidó, confundió y falseó el ser por un ente. En dicho tratado, la referencia inicial al Sofista de Platón trasluce la problemática del olvido del ser desde el comienzo de la filosofía a través de la conversión del ser (Sein) en ente (seiend) mediante la palabra griega ǒv, la cual no fue comprendida y por este motivo, dicha referencia reactiva la formulación y confrontación

\footnotetext{
${ }^{4}$ Algunos de los escritos que Martin Heidegger dedicó a la interpretación del lógos aristotélico son Interpretaciones fenomenológicas sobre Aristóteles. Indicación de la situación hermenéutica. Informe Natorp (1916), Lógica. La pregunta por la verdad (1925-26) y el "§ 44. Dasein, aperturidad y verdad" de Ser y tiempo (1927). La interpretación de la verdad como Aletheia adquirió una relevancia crucial dentro de los años de 1930-40 con la mira hacia el esclarecimiento de la alegoría de la caverna platónica en los textos De la esencia de la verdad. Sobre la parábola de la caverna y el Teeteto de Platón (1931-32), y La Doctrina platónica de la verdad (1942). Y acerca de la importancia de la comprensión ontológica de la physis griega Heidegger escribe diversas interpretaciones en Los conceptos fundamentales de la metafisica. Mundo, finitud y soledad (1929-30), Introducción a la metafísica (1935), Sobre la esencia y el concepto

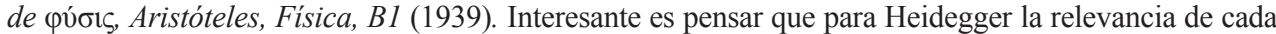
una de esas palabras es el paso para la comprensión del sentido del ser dentro de la interpretación de los antiguos griegos, pero algo distinto ocurre con la exégesis de la palabra "Éóv" debido a que a veces parece ser una palabra secundaria y no digna de un esclarecimiento hermenéutico.
} 
de la pregunta por el sentido del ser en general. ${ }^{5}$ La no comprensión del ser despierta la "gigantomáquia peri tês ousías" (Heidegger, 2006a, p. 25), como esa reactivación de aquello que sigue oculto, pero que, al mismo tiempo, parcialmente se muestra bajo la referencia del "ser del ente", la cual permea la conceptualización tradicional de que la cosa misma del pensar es la más universal, vacía y por ende, evidente.

Ese acercamiento hacia la cosa del pensar tuvo diversas épocas. Heidegger articuló diferentes gramáticas del ser para atender a ese devenir epifánico que se sustrae a todo carácter discursivo y conceptual. Primero, el horizonte del Dasein como ente que comprende el sentido del ser en general se manifestó como ese camino preparatorio que exigía una reconstrucción hermenéutica-histórica para mostrar lo inicialmente oculto. Después, el sendero del regreso a la physis griega posibilitó una recuperación del sentido originario del ser en general desde la paradójica evidencia de que, a pesar de que el mundo griego jamás tuvo una palabra para el ser que Heidegger quiere recuperar, éste se comprendió desde aquello que se manifiesta o emerge de sí mismo en su carácter de salir o brotar a la luz, phýein. ${ }^{6}$ Y más tarde desde la historia del ser, Heidegger pensó el lugar del ser como la plaza abierta (Figal, 2008, p. 218) que trasluce la acuñación de las palabras Lichtung y Ereignis, como despejamiento de la cuadratura del ser, como regalía, morada, casa del ser en general. ${ }^{7}$

\footnotetext{
${ }^{5}$ Relevante es la opinión que sostiene Michael Gelven acerca del comienzo de Ser y tiempo mediante la referencia al pasaje del Sofista de Platón como esa "primera página sin título", la cual trasluce la revolución ontológica de Heidegger. M. Gelven (1989, pp. 21-22) dice hay tres puntos en dicha nota: 1. El pensamiento de Heidegger no es una continuación o reinterpretación del análisis del ente (seiend) que se desarrolla en el Sofista, sino que su investigación se dirige hacia el ser (Sein) y con ello, la investigación ontológica de la fenomenología hermenéutica se distancia del pensar griego; 2. El problema del ser proviene de la tradición del pensamiento occidental, esto hace que la investigación ontológica sea una auténtica confrontación con el pasado; 3 . El tratado fundamental de Heidegger tiene como hilo conductor el reconocimiento de que el significado del ser es un problema y éste es analizado desde la comprensión del ente que pregunta por el ser, Dasein.
}

${ }^{6}$ Interesante es la opinión de Stanley Rosen acerca de esta insignia del ser heideggeriano: "This is evident from the fact that there is no single word in Greek that corresponds to Being (Sein) as Heidegger employs it." (2002, p. XV).

${ }^{7}$ Se puede comprender el pensamiento de Heidegger desde tres épocas: la época de los años veinte y su síntesis en el tratado Ser y tiempo de 1927; la época de los años treinta y la referencia hacia el entender el ser como la totalidad del ente experimentada por la physis griega; y la época que surge desde finales de los años treinta, la cual articula las palabras Ereignis, Lichtung y Aletheia para pensar la relación de "ser" y "tiempo", de "tiempo" y "ser" dentro de la conjunción "y". Esta clasificación del pensar heideggeriano es sostenida por Günter Figal (1998), Modesto Berciano (sentido, verdad, lugar) (1991/2001), Franco Volpi (2012). Por su parte, Friedrich Wilhelm von Herrmann (1997) concibe el pensamiento integral de Heidegger como un único proyecto que sufrió de "transformaciones" (Wandlungen) (1998, p. 7), de una "mutación inmanente (immanenter Wandel)" (1997, p. 71) en su elaboración inicial, pero que en el fondo obedece al plan original trazado por su autor en el §8 del tratado fundamental Ser y tiempo; de tal manera que, la tesis central de Herrmann es que hay algo así como una inflexión o un camino transformado (Kehre) del proyecto inicial de la pregunta por el sentido del ser en general a través de un vuelco (Umschlang) de la Ontología fundamental ( $1^{\mathrm{a}}$ y $2^{\mathrm{a}}$ sección de Ser y tiempo), a la Metaontología ( $3^{\text {a }}$ sección de Ser y tiempo desarrollada en Los problemas fundamentales de la fenomenología de 1927) y posteriormente al pensar del Ereignis como historia del ser (Aportes a la filosofía. Acerca del evento de 1936). 
El Heidegger tardío comprendió la palabra "ser" desde diferentes experiencias del pensar previas al inicio de la metafísica, la cual se presenta como una determinación histórica del olvido del ser. ${ }^{8}$ A partir de las exégesis de los libros fundamentales que conforman la filosofía antigua, el pensador de la Selva Negra marca este inicio a partir de los posicionamientos filosóficos de Platón y Aristóteles, los cuales iniciaron una nueva forma de pensar y con ello, realizaron un giro a las palabras de la experiencia original del ser. Este inicio marcó el destino de la filosofía como filosofía primera y repercutió a lo largo de las diferentes épocas del quehacer filosófico, de tal manera que, cada pensador concibió las directrices del ser y de lo ente desde la misma constitución metafísica iniciada por los pensadores de la antigua Grecia. La misma dinámica se presenta dentro de la filosofía de Nietzsche, la cual, a pesar de su crítica a las categorías de la metafísica como nihilismo y cristianismo, siguió - para la óptica de Heidegger-inmersa dentro de la constitución de la historia como olvido del ser, y con ello, fue catalogada como platonismo invertido.

El trabajo hermenéutico de la tradición filosófica es el camino que abre diferentes posibilidades para pensar históricamente el ser en general. Una vez que Heidegger en los años cuarenta se ocupó de la filosofía nietzscheana y la colocó dentro de la tradición de la metafísica y como la última configuración de la misma, decide ir más allá de la interpretación de los filósofos de la tradición, y con ello, mira hacia los presocráticos para encontrar con ello, los gérmenes, las huellas, las directrices, los caminos olvidados que podrían posibilitar una mirada ontológica hacia el auténtico e inicial proyecto del ser como ser en general; esto es, antes del inicio, antes del comienzo, antes de la instauración de los conceptos que dominaron $\mathrm{y}$ articularon el pensar occidental.

Una de esas palabras originarias del ser es la palabra ćóv. Y esto lo digo porque dentro de la interpretación heideggeriana de los presocráticos varias son

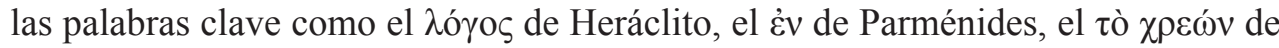
Anaximandro. Cada una de ellas expresa lo mismo. Este es el salto hacia el inicio del pensar, el retorno hacia las primeras palabras conductoras las cuales articulan y vivifican lo ya caduco a través de la temporalidad de la hermenéutica que puede proyectar y regresar por medio de los textos filosóficos a los senderos de lo más inicial y hacia la prehistoria de la metafísica; para con ello, obtener una directriz fundamental acerca de lo más digno de ser pensado.

Se puede decir que dicha palabra fundamental no fue considerada por Heidegger dentro de los escritos, lecciones y seminarios precedentes al tratado

\footnotetext{
${ }^{8}$ Desde la aparición de la segunda obra fundamental de Heidegger Aportes a la filosofía. Acerca del evento de 1936, la palabra "Ereignis" se convierte en la directriz principal para la investigación fenomenológica del ser en cuanto ser; es decir, sin referencia al ente. Difícil resulta traducir adecuadamente al español dicha palabra, algunos la entienden como "evento", "acaecimiento propicio", "acaecimiento apropiador", "acontecimiento".
} 
fundamental Ser y tiempo, ya que ella desde la década de los años cuarenta comienza a ser intensamente interpretada a partir de las diferentes exégesis a la tradición filosófica y particularmente dentro de la interpretación de la filosofía antigua y el retorno a los presocráticos y los antiguos poetas, los cuales abren el camino hacia un "nuevo inicio" o un "retorno al pensar original". Después de Ser y tiempo, Heidegger imparte las lecciones del semestre de verano de 1927 tituladas Los problemas fundamentales de la fenomenología en donde aparece una señal interesante acerca de la palabra Éóv cuando se interpreta el concepto de tiempo de Aristóteles, allí Heidegger dice: "El ćóv es una forma peculiar, intermedia entre la eternidad y el tiempo" (p. 281). Aquí no se dice más acerca de esta palabra. ¿Qué puede mentar el čóv al poseer esa característica fundamental intermedia?, ¿Qué quiere decir y hacia dónde apunta eso? En 1935 en las lecciones Introducción a la metafísica aparece de nuevo la palabra èón y se la menciona dos veces: la primera indicación está expresada dentro de una de las interpretaciones del significado de la palabra lógos en su consideración por parte de la lógica como disciplina escolar, como lógica tradicional y su verdad imperante de la proposición, allí Heidegger dice: "Esto comenzó cuando el čóv, el ser del ente,

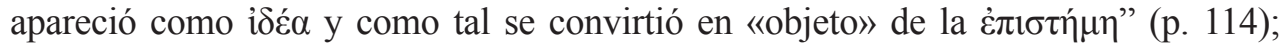

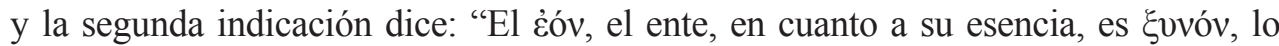
presente y reunido. Govóv no significa «lo general» sino lo que junta y contiene todo en sí mismo" (p. 123). Estas dos indicaciones son interesantes porque apuntan hacia la comprensión del término éóv como palabra conductora de la experiencia del ser del ente porque reúne lo presente bajo una unidad, una totalidad, la cual ya no es articulada con la aparición de los conceptos fundamentales de la metafísica que arrancan desde

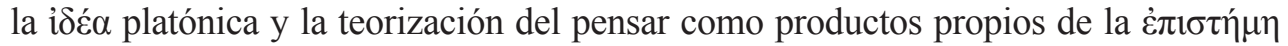
griega. En 1939 en el escrito "Sobre la esencia y el concepto de $\varphi v ́ \sigma l \varsigma$, Aristóteles. Física B1" (2001b) Heidegger piensa en el ćóv a partir de la palabra conductora del pensar de Aristóteles, physis, la cual se presenta como ese estado que contiene la experiencia inicial del ser. ${ }^{9}$ Desde ahí, se piensa en la palabra ćóv como lo que puede guiar la interpretación filológico-ontológica del ser. Desde esta consideración, la confrontación heideggeriana con las filosofías de Platón y Aristóteles es construida desde una ambigüedad hermenéutica que expresa que en ellas está el comienzo del olvido del ser, y al mismo tiempo, esa transformación de los conceptos básicos de la metafísica contiene palabras que hablan acerca de una gramática del ser que pervive como es en el caso de la experiencia de la physis.

\footnotetext{
${ }^{9}$ Este escrito de 1939 constituye una pieza clave para la interpretación del pensamiento de Heidegger, se puede decir que con él se hace época para la investigación ontológica debido a que cierra y abre una etapa dentro del proyecto de la destrucción (Destruktion) de la metafísica: "El ensayo de 1939 sobre la esencia y el concepto de physis en Aristóteles, la última confrontación orgánica de Heidegger con la obra aristotélica, se sitúa claramente en la atmósfera creada por la lectura de los presocráticos" (Volpi, 2012, p. 182).
} 
Dentro de la trágica exégesis heideggeriana de la filosofía nietzscheana se encuentra en el escrito de 1941 llamado "Esbozos para la historia del ser como metafísica" una indicación que apunta hacia la palabra más fundamental del pensamiento occidental, allí se señala lo siguiente:

(...) Hay que considerar en qué medida el «que» de la existentia no alcanza ya

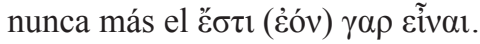

7. La ambigüedad del ćóv y del öv, no pensada de modo gramatical. Qué quiere decir, inicialmente pensado, lo nominal (el ente mismo) y lo verbal (el ser).

Como la ambigüedad del öv incluye la distinción”. (2000b, p. 376).

La distancia entre el discurrir de los modernos y los antiguos representa la imposibilidad para pensar la diferencia ontológica que se sostiene entre el "que" de la existencia y el "qué" de la cuestión del ser. La metafísica de la voluntad de la modernidad (Kierkegaard, Schelling, Hegel, Nietzsche) a partir de la investigación de la "existentia" no puede atisbar ni recuperar el significado originario del sentido del ser que fue pensado dentro de las palabras clave de la antigüedad (Heidegger, 2015a, p. 309). En la referencia anterior, Heidegger expresa que la Modernidad no puede comprender el sentido del ser como éóv. éste aparece formulado enigmáticamente como aquello que no fue pensado por la tradición filosófica, de ahí proviene su ambigüedad y su confusión dentro del terreno de la gramática al colocarse lo nominal y lo verbal de manera no ontológica; es decir, sin la consideración fundamental de la diferencia ontológica de ser y ente. Pero de la misma manera en que apareció la palabra en los escritos antes mencionados, en estos apuntes del año de 1941 se encuentran meras indicaciones que parecen anunciar algo relevante dentro de los análisis de la tradición filosófica. No es sino hasta 1946 en el escrito intitulado "La sentencia de Anaximandro" (2008a) en donde se encuentra un análisis hermenéutico de la enigmática palabra "દ́óv" en su relación directa con la palabra "ón" que designa la experiencia griega del ente. Este texto contiene una intensa producción interpretativa acerca de esta palabra directriz propia de la hermenéutica de los textos fundamentales de la tradición filosófica. ¿Hacia dónde nos conduce este misterioso tratamiento de la palabra griega éóv?, ¿Qué relevancia y función posee esta palabra fundamental para la comprensión del pensamiento heideggeriano acerca del sentido del ser en general como historia del ser?

\section{III}

En su interpretación de la filosofía griega Heidegger aclara que Parménides, Heráclito, Anaximandro piensan auténticamente el ente (őv) desde la experiencia originaria del ser; esto es, antes de cualquier representación medieval o moderna del 
ente como objeto, cosa, realidad efectiva; pero también, previamente a la concepción platónica-aristotélica del ente como presencia, comparecencia o permanencia

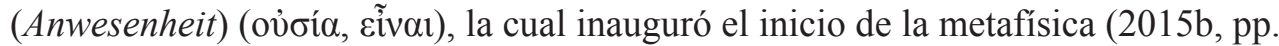
46-48). La versión propia de la historia del ser toma a estos pensadores no como las figuras previas (pre-socráticos o pre-platónicos) de la filosofía occidental, sino como los auténticos pensadores que pudieron intuir la significación del ser y del ente. Esta experiencia inicial fue constituida a través de tres aspectos fundamentales del ente. El primero es que al mentar la palabra "ente" (őv $\tau \alpha$ ), los griegos lo comprenden como la multiplicidad de lo que asiste a la presencia en su reunión y totalidad. El segundo aspecto marca la relación del ente como "lo ente" (őv), el cual es comprendido como lo singular. El tercero es que a la palabra "ente" (őv $\tau \alpha$ ) y a la palabra "lo ente" (őv) les son inherentes una comprensión en el verbo "ser" (Ẽ̃val) (Heidegger, 2008a, pp. 255-256). De esta manera, Heidegger subraya que cuando en la experiencia cotidiana de los griegos se apelaba a la palabra "ente" se daban simultáneamente las tres significaciones de la multiplicidad, la singularidad y su estado temporal como forma verbal. ${ }^{10}$ Esta interconexión marca una experiencia unificada de aquello que se nombraba como "lo ente" mismo, una experiencia que contenía el significado total como dado en una sola e inmediata intuición del ser.

En el pensar de Platón y Aristóteles la palabra "ente" (őv) ya no aparece articulada como la unidad de lo singular, la multiplicidad y la forma verbal, sino que se escinde en significados diferentes y, con ello, en diversas regiones de lo ente; de esta manera, la palabra "ente" (őv) se convierte en un término conceptual, su remisión al estado temporal se pierde, provocando que la noción del ser (Ẽvval) sea vista desde la permanencia y constancia de la presencia (Anwesenheit) y, por ende, que dicho ser sea entendido posteriormente a partir de las cuatro tesis metafísicas: el ser no es un predicado real (Kant), el ser como esencia y existencia (tradición medieval-aristotélica), el ser como el ser del espíritu y de la naturaleza (Descartes), y el ser de la cópula de la tradición lógica (Herrmann, 1997, pp. 49-50/ Heidegger, 2000a). Desde 1931 se anunciaba dicha remisión metafísica al ser como lo permanente: "Esta presencia, con todas sus variaciones y en toda su ampliación,

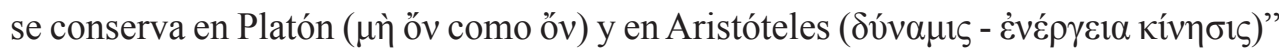
(2015b, p. 46). Bajo esta comprensión de lo ente será labrada la separación de lo óntico y lo ontológico, una separación que escinde; es decir, que olvida la referencia ontológica porque se queda en lo puramente óntico ocasionando que la experiencia

${ }^{10}$ Esta diversidad del significado de la palabra "ente" de los antiguos pensadores griegos recuerda ineludiblemente la actitud propia del método de la fenomenología en su investigación acerca del múltiple significado del ser bajo la cual Heidegger fue iniciado a través de las lecturas de las Investigaciones Lógicas (1900-01) de Husserl y el libro Del múltiple significado del ente según Aristóteles (1862) de Franz Brentano, los cuales fueron tomados como punto de partida para erigir la actitud, el método y los alcances de esa ciencia fundacional que emergió en el siglo XX. 
y la intuición originaria del ser se pierda dentro de lo ente. Este fue el momento crucial que ejecutaron las filosofías de Platón y Aristóteles, las cuales dieron las condiciones de posibilidad del olvido del ser a través del momento histórico del traspaso de las palabras fundamentales del pensar griego al latín: la verdad como

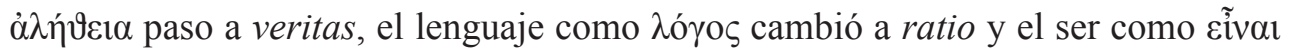
devino en esse (Heidegger, 2005). ${ }^{11}$

Dentro del viraje del pensar dentro de la prehistoria de la metafísica, en el escrito "La sentencia de Anaximandro" (2008a) Heidegger prosigue su indagación que apunta hacia una interpretación de la comprensión de la palabra griega para lo "ente" (óv) y de la forma en que ésta se muestra en su relación con la palabra

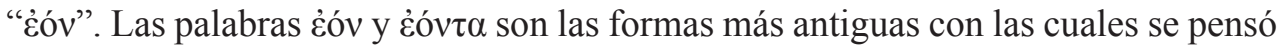
la experiencia de lo ente en su múltiple significación de lo singular, lo universal y lo verbal; pero en ellas ( $\dot{\varepsilon} o ́ v$, Éóv $\tau \alpha$ ), la letra $\dot{\varepsilon}$ señalaba la co-pertenencia entre el

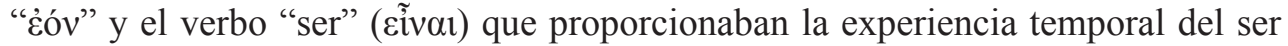
(Heidegger, 2008a, p. 255). Así, la palabra "غ̇óv" comprende la relación mutua entre el "ente" (őv) y el "ser" (Ẽ̃val). Por lo que, al colocar la unión de lo ente (őv) y el ser (Eĩval) por medio de la palabra èón se busca el pliegue del ente y del ser. Pero ¿qué significa esta palabra para la reflexión de los pensadores iniciales? En las lecciones de 1952 tituladas ¿Qué significa pensar?, se dice lo siguiente:

"La palabra, analizada gramaticalmente, es un participio. Nuestra reflexión ha mostrado que éóv es el participio de todos los participios. El ćóv es la singular y, en

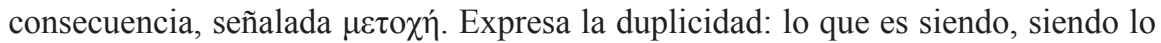
que es" (2008b, p. 231). ${ }^{12}$

Y en un artículo contemporáneo a estas lecciones llamado "10. Moira (Parménides VIII, 34-41)" se apunta hacia la misma idea de la gramática del ser: "El ćóv, el ente, está pensado más bien en el pliegue de ser y ente, y formulado de un modo participal, sin que el concepto gramatical intervenga propiamente en el saber del

\footnotetext{
${ }^{11}$ Heidegger en su escrito "El final de la filosofía y la tarea del pensar" (2003b, p. 77) dice que toda filosofía es metafísica, y esto quiere decir que toda la filosofía ha olvidado el ser en general. El inicio de la filosofía es el inicio del olvido del ser y éste comienza con el pensar de Platón y Aristóteles y la transformación latina de sus conceptos fundamentales.

${ }^{12}$ Raúl Gabás, traductor de la versión de Max Niemeyer Verlag (1954) de ¿Qué significa pensar?, traslada la frase participal "Seiendes seiend: seiend Seiendes" como un gerundio "lo que es siendo, siendo lo que es", y en una cita expresa que esto se debe a la obligación de señalar lo siguiente: "la acción por la que el ser actúa desde el ente y, por otra parte, la acción del ser pasa a constituir el ente" (p. 231). En este caso, considero que para captar mejor la significación que Heidegger desea imprimir a la comprensión participal del ser como éóv es indispensable pensar que la acción del ser hacia el ente y del ente hacia el ser acontece como una actividad constante, como algo que acontece, y no como algo que en cualquier instante deja de ser. La palabra en desuso "eseyente" y la palabra "esente" podrían aproximarnos también a esa idea.
} 
lenguaje" (2001a, p. 177). Es relevante indicar aquí que la palabra griega èón como el participio de todos los participios es comprendida a partir del término alemán "Zwiefalt" (Heidegger, 2000c, p. 245 / Heidegger, 2002, p. 231), la cual en las precedentes referencias fue traducido como "duplicidad" y "pliegue". ${ }^{13}$ La palabra "Zwiefalt" es el «pliegue» del ser y del ente; y el «despliegue del pliegue» "das Entfaltende der Zwiefalt" (Heidegger, 2000c, p. 245) es la separación históricometafísica de ser y ente, y su subsecuente confusión metafísica del ser por el ente. ${ }^{14}$ El pliegue es la mutua reciprocidad con la cual el ser y el ente se encuentran atados, aunque el ente es debido a que el ser está en él ya pre-comprendido, pero el ser jamás podrá ser un ente; el pliegue de ser y ente es un destino bajo el cual ambos están atados. Por ello, todas las interpretaciones que vierten la palabra "èón" como lo "ente" carecen de total fundamento; para Heidegger el èón no mienta lo ente, pero tampoco piensa el ser en sí mismo, sino que contiene la duplicidad, pliegue o juntura que hace comprender tanto el "«ser del ente» y «ente en el ser»" (Heidegger, 2001a, p. 177) bajo la expresión "lo que es siendo, siendo lo que es" (2008b, p. 231).

Dicha formulación gramatical contiene la señal más esencial del lenguaje especulativo alemán en su inflexión verbal del participio que contradictoriamente nos aproxima a la significación como un movimiento de las cosas mismas. Es la puesta

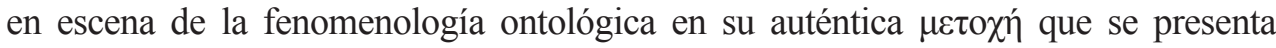
como el hilo conductor de la interpretación del ser desde un punto de vista gramatical:

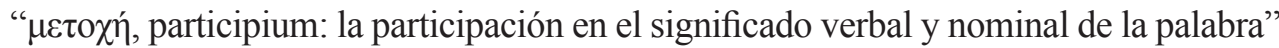
(Heidegger, 2008a, p. 256). La flexión verbal del participio debe ser captada desde la reflexión de la cosa misma del pensar y con ello, por medio de la potencialidad del lenguaje que bajo una única indicación nominal y verbal marcha hacia los terrenos propios de la experiencia humana del pensar y se traslada con ello, más lejos de la mera expresión porque potencializa la vivencia misma que las palabras afloran y comunican para el mundo de la vida, visto éste desde el ámbito perteneciente a una fenomenología de la vida, la cual es incorporada y reactivada desde la gramática del ser.

En referencia a esto y en continua indagación con lo anteriormente dicho, se prosigue en "10. Moira (Parménides VIII, 34-41)" con algunas indicaciones sobre el pliegue que le es inherente a dicho participio:

\footnotetext{
${ }^{13}$ Raúl Gabás traduce el término alemán "Zwiefalt" como "duplicidad" (Heidegger, 2008b, p. 231); mientras que Eustaquio Barjau lo traduce como "pliegue" (Heidegger, 2001a, p. 177).

${ }^{14}$ El juego de palabras entre "Zwiefalt" y "das Entfaltende" es crucial porque contiene la dinámica pura de la juntura de ser y ente como "el despliegue del pliegue". Interesante es pensar en que ese despliegue está nominalizado participialmente; es decir, hay una acción de desplegar y plegar al mismo tiempo. El despliegue del pliegue (das Entfaltende der Zwiefalt) se podría traducir literalmente como "lo desplegado del pliegue", pero esto únicamente si se entiende que "lo desplegado" se reflexiona continuamente en una acción presente.
} 
El pliegue se puede por lo menos indicar por medio de los giros «ser del ente» y «ente en el ser». Ahora bien, lo que se despliega, más que indicarnos su esencia, lo que hace es ocultarse por medio del «en el» y del «del». Los giros están muy lejos de pensar el pliegue como tal, o incluso de elevar el despliegue del pliegue a lo digno de ser cuestionado. (2001a, p. 177)

Ese despliegue del pliegue permanece no pensado desde la experiencia de la metafísica entendida como momento histórico del olvido del ser. La manera en que se alcanza una comprensión del despliegue del pliegue se piensa desde la significatividad del participio del ċóv. En ¿Qué significa pensar?, se intenta captar el movimiento hermenéutico acerca del ser desde la experiencia ontológica-gramatical mediante la utilización de los participios en las palabras "floreciente" y "fluyente" (pp. 181-182). La primera palabra "floreciente" significa "algo que florece", y al mismo tiempo, el "florecer" como actividad presente; para la palabra "fluyente" el uso del participio significa "algo que fluye", y al mismo tiempo, ella remite al "fluir" en su estado puro. Este uso del participio encierra una significación nominal y una verbal. La palabra "غ̇óv", como el participio más fundamental, significa "lo que es siendo" y, al mismo tiempo, mienta el estado de "siendo lo que es"; es decir, dicho participio contiene la experiencia del despliegue del pliegue dentro de los giros "ser del ente" y "ente en el ser", como una relación nominal y verbal que aparece significada bajo la misma intuición del ser. El ser como \&̇óv, dentro de la experiencia que salta la historia del ser como metafísica, es la palabra más fundamental que la fenomenología-ontológica-hermenéutica de Heidegger ha concebido dentro de su actitud radical del "ir a las cosas mismas" (Zu den Sachen selbst!), las cuales se hallan dentro de los textos de la filosofía y de la gramática del ser que pervive en ellos. ${ }^{15}$ El destino de occidente depende de la comprensión de dicha palabra (Heidegger, 2008a, p. 256).

En el çóv se encuentra la unión entre el ser y el ente. En "La sentencia de Anaximandro" (2008a, pp. 255-256) Heidegger realiza una interpretación de Homero en donde es pensada la forma más originaria bajo la cual se entiende el ćóv en su seña esencial. Precisamente cuando en la Ilíada aparece la figura del vidente Calcante al adivinar la suerte en la que sucumbirán los aqueos, su visión se vuelve hacia lo pasado, lo presente y lo futuro. ${ }^{16} \mathrm{El}$ juego de palabras de estos modos temporales se encuentra determinado por el દ́óv. Para lo presente como lo

\footnotetext{
${ }^{15}$ Es notable remarcar que después de Ser y tiempo, el proceder de Heidegger sigue siendo fenomenología en cuanto método de investigación acerca del ser en general (Herrmann, 1997), que su meditar permanece pensando ontológicamente en cuanto a su tema fundamental, y que su manera de reflexión interpretativa sigue siendo hermenéutica con el desplazamiento de la hermenéutica de la ontología fundamental del Dasein hacia la hermenéutica de los textos fundamentales de la historia del ser.

${ }^{16}$ Cf. "Tras hablar así, se sentó; y entre ellos se levantó el Testórida Calcante, de los agoreros con mucho el mejor, que conocía lo que es, lo que iba a ser y lo que había sido" (Homero I, 69 y ss. Cf. 1991, p. 159).
} 


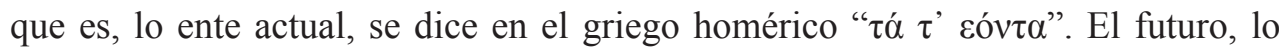

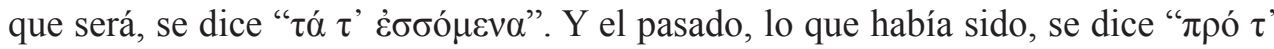

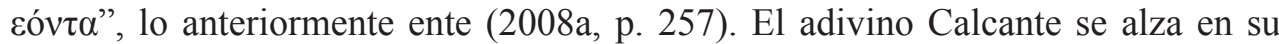
visión para ver en una intuición todo el ámbito del tiempo, lo actualmente presente y lo no actualmente presente como pasado y futuro. Esta es la señal fundamental en donde el źóv llega a ser comprensible a partir de la unidad intuitiva originaria de pasado, presente, futuro; y él, en este punto, alcanza al parecer un rasgo similar al fenómeno originario de la unidad extática, "ekstatische Einheit" (Luckner, 2001, p. 138), del tiempo propio del Dasein expuesto en el "§ 65. Temporeidad como sentido ontológico del cuidado" del tratado fundamental Ser y tiempo en donde se especifica la característica esencial del fenómeno del tiempo como temporeidad:

Futuro, haber-sido, presente, muestran los caracteres fenoménicos del "hacia-sí" <“Auf-sich-zu">, del "de-vuelta-a" <"Zurück auf"> y del "hacer-comparecer-algo" <"Begegnenlassen von>. Los fenómenos del "hacia...", del "a...", del "en medio

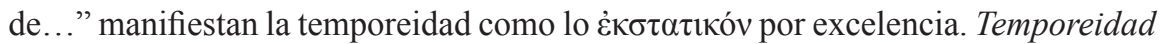
es el originario "fuera de sí", en y por sí mismo. Por eso, a los fenómenos de futuro, haber-sido y presente ya caracterizados los llamamos éxtasis de la temporeidad. La temporeidad no es primero un ente que, luego, sale de sí, sino que su esencia es la temporización de la unidad de los éxtasis" (p. 346).

Esta unidad de los éxtasis del tiempo fue pensada como la conjunción de las dimensiones o modos del tiempo (futuro, haber-sido, presente) como un «fuera de sí en y por sí mismo», “»Ausser-sich« an und für sich selbst”" (Heidegger, 1977, p. 435). Desde la hermenéutica del Dasein, este tiempo originario se experimenta como un "futuro que está siendo sido y que presenta" (Heidegger, 2006, p. 344), y su carácter extático posee el sentido de salir y retornar al modo de un juego dentro de sus modos temporales:

“«Extático» significa poder separarse de algo, poder superarse, y en efecto eso permite que se diga de los modos del tiempo - cada uno de ellos es sólo de tal manera que él simultáneamente se supera también, que él «regresa» (»umschlägt«) en los otros modos del tiempo, ninguno es sin los otros." ${ }^{17}$ (Figal, 1992, p. 81)

Este carácter extático de la unidad temporal del tiempo que se temporaliza en sus modos de ser posee la particularidad de "regresar" (umschlagen) a partir de la tendencia proyectante del futuro y su retorno al pasado como modo auténtico de la temporeidad. El presente como instante (Augenblick) posibilita que el tiempo

17 ,»ekstatikós« heisst, sich von etwas trennen können, über sich hinausgehen können, und das lässt sich von den Formen der Zeit in der Tat sagen - jede von ihnen ist nur derart, dass sie zugleich auch über sich hinaus ist, dass sie in die anderen Formen der Zeit »umschlägt«; keine ist ohne die anderen". La traducción y el subrayado son míos. 
acontezca como un «fuera de sí en y por sí mismo» y que su dinámica sea un separarse, superarse y regresar al modo de un «dejar comparecer algo»; pero este algo no es un ente y no posee el sello de la determinación metafísica del ser como presencia (Anwesenheit) anclada en el eterno presente, ni del constante devenir del proceder de la dialéctica (Aufhebung) de la historia del espíritu, ni mucho menos del tiempo cíclico del eterno retorno de lo mismo; sino que, ese tiempo del instante se temporaliza y, con ello, muestra su característica esencial como finitud.

El esencial carácter extático del tiempo del Dasein acontece en el instante (Augenblick) que se presenta como un espacio de juego de ser y tiempo. Este carácter instantáneo de la finitud del tiempo abre una correlación futura con el carácter epocal del ser propio del pensamiento posterior del tratado fundamental de Ser y tiempo. ${ }^{18}$ A partir de esto, la fenomenología ontológica del pensar heideggeriano configura una determinada hermenéutica dentro de la historia del ser y sus correspondientes épocas, y con ello, apunta hacia el sentido temporal del pliegue de ser y ente, el cual articula no sólo el estado nominal y verbal de la intuición del ser, sino que indica su estado temporal a partir de la conjunción de los ámbitos del tiempo que acontecen en el estado de abierto del ser mismo que se presenta como un acontecer o un destino acaecido: el ser está aconteciendo temporalmente y, por ende, algo acontece como ente.

La intuición del čóv, como morada de los modos y dimensiones del tiempo, lleva a la visión del adivino Calcante a una sola y única presentificación, y con ello, todo el sentido del ser y el tiempo advienen en una presencia al modo de un golpe, latigazo, latido (der Schlag), el cual finitamente sale y regresa (umschlagen) de forma inmediata en un juego temporal. Ese golpe de la temporalidad del ser lo experimentó Heidegger en su estancia en las islas griegas, el lugar bajo el cual los dioses moraban y se demoraban en su contacto con los hombres, él expresa que: "Recuerdo una tarde durante mi estancia en Egina. De repente escuché (vernahm) un solo relámpago, al que después ningún otro sucedió. Mi pensar fue: Zeus". ${ }^{19}$ Esa

\footnotetext{
${ }^{18}$ Cf. „Der ekstatische Charakter des Da-seins jedoch ist die für uns zunächst erfahrbare Entsprechung zum epochalen Charakter des Seins. Das epochale Wesen des Seins ereignet das ekstatische Wesen des Da-seins. Die Ek-sistenz des Menschen steht das Ekstatische aus und wahrt so das Epochale des Seins, zu dessen Wesen das Da uns somit das Da-sein gehört“ (Heidegger, 1997b, p. 338). Mi traducción dice: "Pero el carácter extático del Da-sein está para nosotros muy cerca de una correspondencia experimentable con el carácter epocal del ser. La esencia epocal del ser acontece apropiadoramente en la esencia extática del Da-sein. La ex-istencia del hombre soporta lo extático y guarda así lo epocal del ser, cuya esencia nos relaciona con el Da y, por consiguiente, con el Da-sein" (Heidegger, 1997, p. 338).

19 „Ich erinnere mich an einen Nachmittag während meines Aufenthaltes auf Aegina. Plötzlich vernahm ich einen einzigen Blitzschlag, auf den dann kein weiterer erfolgte. Mein Gedanke war: Zeus“ (Heidegger \& Fink, 1970, p. 13). La traducción y el subrayado son míos.
} 
intuición experimentada a través del "escuchar" o "percibir" (vernehmen) ${ }^{20}$ aparece como una donación total del fenómeno mismo en el relámpago (Blitzschlag), el cual acontece como un golpe instantáneo (Schlag) bajo el cual la totalidad es gobernada -esto, recordando el contexto de las palabras dentro de la exégesis del fragmento 64 de Heráclito: el rayo como mirada del ser, “der Blick des Seins” (Heidegger, 1977b, p. 338). ${ }^{21}$ La "visión del rayo", la "mirada del ser", la "intuición fenomenológica" son experimentadas no sólo por el percibir fenomenológico en cuanto tal, sino por el percibir como un escuchar (vernehmen) el relámpago, como un escuchar el dictado del ser, como un esperar el llamado del ser, bajo el cual todo acontecimiento es templado por el rayo porque en medio de la lozanía de la tarde y de la luz del sol, Zeus hace aparecer y desaparecer las cosas, cambia el día en noche, el verano en invierno, la presencia en ausencia como un juego entre mortales y dioses, tierra y cielo. ${ }^{22}$ La visión del adivino Calcante y la visión del golpe del rayo no son un mero contemplar o percibir, sino un percibir escuchando bajo el cual se da la versión heideggeriana de la experiencia del ser entre los griegos.

Esta interpretación del çóv desde el ámbito de la temporalidad del ser recuerda la influencia husserliana en la ontología fenomenológica. En 1962 en el escrito "Mi camino en la fenomenología" (2003b, p. 99) Heidegger hace rememorar la importancia de la intuición categorial de las Investigaciones Lógicas de Husserl bajo la cual se proporcionaba el significado del ser desde una intuición fundacional que proporciona sentido y constitución a las cosas. ${ }^{23}$ Allí, en la "fenomenología descriptiva" husserliana, la intuición del ser no se da en la percepción porque el ser no es nada perceptible, tampoco se da en el juicio debido a que el ser no se constituye como un predicado real, ni se ofrece como una síntesis del enlace de la proposición, ni mucho menos se construye desde las operaciones de la reflexión interna que lo

${ }^{20} \mathrm{Cf}$. El percibir "vernehmen" que Heidegger en 1931 reconoce de la fenomenología y su precedente en los griegos: "Una cosa sí lograron los fenomenólogos (Husserl y Scheler): despertaron la percepción inmediata (vernehmen), que estaba vuelta a las cosas mismas (una intuición dirigida a la esencia), y eso ya era algo propio de la postura de la Antigüedad" (2015b, p. 47). La indicación entre paréntesis es mía.

${ }^{21}$ La interpretación del fragmento 64 de Heráclito es crucial para Heidegger debido a que el rayo (Blizt) es una palabra conductora para la experiencia de la referencia ontológica de ente y ser. Heidegger dice en "La sentencia de Anaximandro" (2008a, p. 251) que el rayo (Blitz) es la mirada (Blick) del ser. Este juego de palabras entre "rayo" y "mirada" constituye un punto central para la experiencia fenomenológica del ser como juego de ocultación y desocultación a través de la intuición de ser.

${ }^{22} \mathrm{Cf}$. La obra Aportes a la filosofía. Acerca del evento de 1936 en donde el pensamiento heideggeriano comprende el ser como "evento" (Ereignis), el cual establece el juego de la cuadratura o cuaternidad entre la contienda de "mundo-tierra" y "mortales y dioses" (2006b, p. 253).

${ }^{23}$ Heidegger en "Mi camino en la Fenomenología" (2003b, p. 99-100) dice que su contacto con la fenomenología de Husserl está en la etapa de las Investigaciones Lógicas y en especial con la Quinta y Sexta Investigación Lógica, en donde la ejercitación de la fenomenología husserliana tomó como punto principal la "«visión» fenomenológica" como esa intuición que proporciona el "darse a los fenómenos a sí mismos”. 
puedan aproximar a un nominalismo y con ello, a una reflexión empírica de ideas; sino que el ser tiene un origen dentro de un cumplimiento de una intuición categorial y una percepción que ofrece el fenómeno vivido desde él mismo:

Es notorio desde luego que así como otro concepto cualquiera (una idea, una unidad específica) sólo puede surgir, esto es, sernos dado él mismo, sobre la base de un acto que ponga delante de nuestros ojos, al menos imaginativamente, alguna individualidad correspondiente a dicho concepto, así también el concepto del ser sólo puede surgir cuando se nos pone delante de los ojos, real o imaginativamente, algún ser. Si el ser vale para nosotros como el ser predicativo, ha de sernos dada alguna situación objetiva, y, naturalmente, por medio de un acto que nos la dé -acto que es análogo a la intuición sensible en sentido vulgar. (Husserl, 2013, p. 702).

Este poner "delante de los ojos" un ser contiene la idea de que el ser mismo se ofrece desde la inmediatez de una intuición fundante o categorial, la cual se presenta como la vía de acceso a un fenómeno en su estado puro y total. Husserl dentro de la "Sexta Investigación Lógica" (2013) pone el acento en la intuición categorial como esa inmediatez que hace aparecer en el acto el "ser" mismo. En la fenomenología ontológica de Heidegger, la visión del adivino Calcante sería como esa "«visión» fenomenológica" (2003b) que proporciona la cosa tal y como es, pero la diferencia con respecto a la óptica del ser husserliano consiste en la exposición de los fenómenos desde la temporalidad y la asistencia del tiempo desde el ámbito de la finitud o de la presencia temporalizada (Anwesen) como ese rasgo que hace aparecer el ser en sus formas de tiempo. Calcante puede comprender el destino de los aqueos porque visualiza dicha presencia en el ćóv desde una única visión originaria, una "«visión» temporal del ser", la cual no recae en una subjetividad fenomenológica, sino que es vista desde la ontología de las cosas mismas. El participio de todos los participios muestra el fenómeno mismo desde el despliegue del pliegue de ser y ente, desde el devenir del ser que es captado por el movimiento en todas sus manifestaciones, y desde la intuición del tiempo que transporta el despliegue de las cosas mismas en su luz como juego del ser.

\section{IV}

Heidegger llama "presencia" (Anwesen) a la conjunción del tiempo del غ̇óv, la cual no es la misma a la presencia (Anwesenheit) como comparecencia o permanencia de la tradición metafísica; sino que ella es la presencia temporalizada, que recibe también el nombre de la hacienda o casa. Y a partir de esta significación es como se interpreta el sentido originario del ćóv como ser. Por eso, Heidegger señala: "El pensamiento griego ya antes de su comienzo mora en la acción del દ̇óv como presencia de lo que se hace presente" (2008b, p. 193). La presencia es el elemento en que aparece la palabra más antigua para el ser en el pensar occidental 
y establece los correlatos directos con el tiempo. En "10. Moira (Parménides VIII, 34-41)" se dice sobre el ser: "Si es que es legítimo hablar de la historia acontecida del ser, entonces debemos haber pensado antes que Ser quiere decir: presencia de lo presente: pliegue" (2001a, p. 186). El غ̇óv, ser, es la presencia de lo presente (Anwesen des anwesenden). En donde el tiempo y el ser se pertenecen el uno al otro. Y en donde igualmente, aparece el modo participal en donde la presencia (Anwesen) no es una mera presencia (Anwesenheit), pero hace posible lo presente como lo que asiste dentro de ella.

El ser como presencia "¿́cov" se ofrece como la apertura de lo presente que aparece en su manifestación: "En el despliegue del pliegue, con el brillo de la presencia, aparece lo presente" (2001a, p. 188). La relación entre presencia y presente posee la intuición fenomenológica de la gramática del ser, la cual contiene la formulación verbal y nominal que muestra a los fenómenos tal y como son en sí mismos. Heidegger dice: "De acuerdo con esto દ̇óv significa: presente en el desocultamiento" (2008a, p. 257). Pero la palabra غ̇óv no es un mero presente, ni mera presencia; sino que es la relación entre ellos. La presencia al intentar ser representada ella misma se hace presente, pero ella no es presente, así como tampoco es una mera presencia; ella sería una presencia (Anwesen) que no es presencia (Anwesenheit) porque se sustrae a todo intento de ser un presente, un eterno presente. En la significación del čóv se encuentra pensada la presencia desde la aproximación fenomenológica gramatical de la ontología que hace reformular aquello que Heidegger comprendió de los antiguos griegos con la articulación del despliegue del pliegue del ser y el ente. El participio de todos los participios se presenta como el fenómeno más claro, evidente y compresible que contiene el devenir del ser desde la dinamización de todas sus características fenomenológicas; pero al mismo tiempo, su cercanía produce olvido y confusión, de tal manera que, el despliegue del pliegue se cierra, se olvida o nunca se ha abierto; por esta causa, se dice, acerca del significado del ser propio de la ontología heideggeriana en su regreso al pensar inicial, que: "la relación entre presencia y presente permanece impensada (...). La esencia de la presencia y, con ella, la diferencia de la presencia respecto a lo presente, queda olvidada. El olvido del ser es el olvido de la diferencia entre el ser y lo ente" (Heidegger, 2008a, p. 271).

Estas indicaciones han intentado contribuir con una aproximación hacia el significado de la palabra que designa la intuición del ser como el participio de todos los participios, el cual apunta hacia el sentido del ser dentro del pensamiento de la historia del ser como historia del olvido del ser, del cual no hay nada. Pero con esto, queda establecida la característica ontológica, fenomenológica y hermenéutica de la investigación de la antigua palabra que contiene el pliegue de ser y ente. 
Berciano, M. (1991). "Sinn - Wahrheit - Ort. Tres etapas en el pensamiento de Heidegger" en Anuario Filosófico, 24, pp. 9-48.

Berciano, M. (2001). "La técnica moderna según Heidegger", Sociedad de Lógica, Metodología y Filosofía de la Ciencia en España (SLMFCE). 25-26. Verano 2001 / Invierno 2001-2002. Valencia: Universidad de Valencia.

Figal, G. (1992). Martin Heidegger zur Einführung. Hamburg: Junius Verlag GmbH.

Figal, G. (2008). "Heidegger y la Fenomenología" en Duque, Félix. (ed.). Heidegger. Sendas que vienen. Vol. 1, pp. 205-226. Madrid: Ediciones Pensamiento-UAM.

Gelven, M. (1989). A Commentary on Heidegger's Being and Time. DeKalb, Illinois: Northern Illinois University Press.

Gillespie, M. A. (1983). Hegel, Heidegger and the Ground of History. Chicago-London: The University of Chicago Press.

Heidegger, M. (1977a). Sein und Zeit. GA. 2. Frankfurt am Main: Vittorio Klostermann GmbH.

Heidegger, M. (1977b). Holzwege. GA. 5. Frankfurt am Main: Vittorio Klostermann GmbH.

Heidegger, M. (2000a). Los problemas fundamentales de la fenomenología. Madrid: Trotta.

Heidegger, M. (2000b). Nietzsche II. Barcelona: Ediciones Destino.

Heidegger, M. (2000c). Vorträge und Aufsätze. GA. 7. Frankfurt am Main: Vittorio Klostermann GmbH.

Heidegger, M. (2001a). Conferencias y artículos. Barcelona: Ediciones del Serbal.

Heidegger, M. (2001b). Hitos. Madrid: Alianza Editorial.

Heidegger, M. (2002). Was heisst Denken? GA. 8. Frankfurt am Main: Vittorio Klostermann GmbH.

Heidegger, M. (2003a). Introducción a la metafisica. Barcelona: Gedisa.

Heidegger, M. (2003b). Tiempo y ser. Madrid: Editorial Tecnos.

Heidegger, M. (2005). Parménides. Madrid: Akal.

Heidegger, M. (2006a). Ser y tiempo. Madrid: Trotta.

Heidegger, M. (2006b). Aportes a la filosofia. Acerca del evento. Buenos Aires: Editorial Biblos.

Heidegger, M. (2008a). Caminos de bosque. Madrid: Alianza Editorial.

Heidegger, M. (2008b). ¿Qué significa pensar?. Madrid: Editorial Trotta.

Heidegger, M. (2008c). Identidad y diferencia. Identität und differenz. Barcelona: Anthropos Editorial.

Heidegger, M. (2015a). El tratado de Schelling sobre la esencia de la libertad humana (1809). Buenos Aires: Ediciones Waldhuter. 
Heidegger, M. (2015b). Cuadernos negros (1931-1938). Reflexiones II-VI. Madrid: Editorial Trotta.

Heidegger, M. \& Fink, E. (1970). Heraklit. Frankfurt am Main: Vittorio Klostermann GmbH.

Herrmann, F. W. von. (1988). Der Begriff der Phänomenologie bei Heidegger und Husserl. Frankfurt am Main: Vittorio Klostermann GmbH.

Herrmann, F. W. von. (1997). La «segunda mitad» de Ser y Tiempo. Sobre los problemas fundamentales de la Fenomenología de Heidegger. Madrid: Editorial Trotta.

Homero. (1991). Ilíada. Madrid: Biblioteca Clásica Gredos.

Husserl, E. (2013). Investigaciones Lógicas. Vol. II. Madrid: Alianza Editorial.

Luckner, A. (2001). Martin Heidegger: Sein und Zeit. Ein einführender Kommentar. Paderborn- München-Wien-Zürich: Ferdinand Schöningh.

Rosen, S. (2002). The Question of Being. A Reversal of Heidegger. South Bend, Indiana: St. Augustine's Press.

Volpi, F. (2011). “"Más alto que la realidad está la posibilidad”. La aproximación fenomenológica a la historia de la filosofía en el joven Heidegger” en De Lara, F. (ed.). Entre fenomenología y hermenéutica. In memoriam Franco Volpi. Madrid: Plaza y Valdés, pp. 13-42.

Volpi, F. (2012). Heidegger y Aristóteles. Buenos Aires: Fondo de Cultura Económica. 